Check for updates

Cite this: RSC Adv., 2017, 7, 18347

Received 15th February 2017

Accepted 20th March 2017

DOI: $10.1039 / \mathrm{c} 7 \mathrm{ra01882g}$

rsc.li/rsc-advances

\section{Inhibitory effects of three bisbenzylisoquinoline alkaloids on lipopolysaccharide-induced microglial activation}

\author{
Xue-Lian Meng, ${ }^{a}$ Liang-Chao Zheng, ${ }^{a}$ Jia Liu, ${ }^{a}$ Cheng-Cheng Gao, ${ }^{a}$ Ma-Chao Qiu, ${ }^{a}$ \\ Ying-Ying Liu, ${ }^{a}$ Jing Lu, ${ }^{a}$ Dan Wang ${ }^{b}$ and Chang-Lan Chen (ID *a
}

\begin{abstract}
Activation of microglial cells has been considered to be associated with various neurodegenerative diseases. In this study, three bisbenzylisoquinoline alkaloids (liensinine, neferine, and isoliensinine) were found to inhibit microglial activation induced by lipopolysaccharide (LPS). Liensinine, neferine, and isoliensinine suppressed the release of $\mathrm{NO}$ and cytokines (TNF- $\alpha, \mathrm{IL}-1 \beta$, and IL-6) by LPS-activated microglial cells. Three alkaloids displayed direct NO-scavenging activity in SNP solution and reduced LPS-induced protein and mRNA expression of iNOS in microglial cells. Further studies revealed that liensinine, neferine, and isoliensinine blocked I $\mathrm{KB} \alpha$ phosphorylation and degradation, as well as ROS production in LPS-activated microglial cells. In addition, three alkaloids showed direct scavenging activity against $\mathrm{DPPH}, \cdot \mathrm{OH}$, and $\mathrm{ONOO}^{-}$radicals. These results suggest that liensinine, neferine, and isoliensinine may have potential in the treatment of neurodegenerative diseases accompanied by microglial activation.
\end{abstract}

\section{Introduction}

Microglial cells are macrophage-like cells, and the first and most important line of immune defense in the central nervous system (CNS). ${ }^{1}$ Neurodegenerative diseases such as Alzheimer's disease (AD), Parkinson's disease (PD), and Huntington's disease (HD) are related to neuroinflammation, featured by the release of neurotoxic factors including nitric oxide (NO) and cytokines, such as tumor necrosis factor- $\alpha$ (TNF- $\alpha)$, interleukin1 beta (IL-1 $\beta$ ), and interleukin-6 (IL-6) by microglial cells. ${ }^{2}$ The inhibition of microglial activation may lead to the attenuation of the formation and development of many neurodegenerative diseases. $^{3}$

Nelumbo nucifera (lotus) is a well-known edible plant widely cultivated in Asia. Food related to lotus is popular in East Asia, especially China. As a homology of traditional Chinese medicine and food, the green embryo of Nelumbo nucifera seeds mainly contain three structure-related bisbenzylisoquinoline alkaloids including liensinine, neferine, and isoliensinine (chemical structures shown in Fig. 1). ${ }^{4}$ These three bisbenzylisoquinoline alkaloids are reported to possess a wide range of biological activities including anticarcinogenesis, ${ }^{5-7}$ anti-arrhythmia, ${ }^{8,9}$ anti-hypertension, ${ }^{10}$ sedation, ${ }^{11}$ and anti-depression. ${ }^{12}$

${ }^{a}$ School of Pharmaceutical Science, Liaoning University, Shenyang 110036, China. E-mail: chenchanglanbio@aliyun.com; Fax: +86-024-62202469; Tel: +86-02462202192

${ }^{b}$ Research Center for Natural Product Pharmacy of Liaoning Province, Shenyang 110036, China
Studies have documented that liensinine, neferine, and isoliensinine can cross the blood-brain barrier and have recently received much attention for their neuroprotective effects. ${ }^{13-15}$ Liensinine and neferine have been demonstrated to have anti-AD activities by inhibiting acetylcholinesterase (AChE), butyrylcholinesterase (BChE), and $\beta$-site amyloid precursor proteincleaving enzyme 1 (BACE1). ${ }^{14}$ In addition, neferine attenuates the protein level and toxicity of mutant huntingtin in PC-12 cells via induction of autophagy, which might demonstrate its neuroprotective effect in vitro. ${ }^{15}$ However, the effects and mechanism of liensinine, neferine, and isoliensinine on the inflammatory activities of microglial cells remain to be unclear.<smiles>COc1ccc(C[C@@]2(C)c3cc(Oc4cc(C[C@H]5c6cc(O)c(OC)cc6CCN5C)ccc4O)c(O)cc3CCN2C)cc1</smiles>

$\mathrm{R}_{1}=\mathrm{H}, \mathrm{R}_{2}=$ Me: liensinine (1)

$R_{1}=R_{2}=$ Me: neferine (2)

$\mathrm{R}_{1}=\mathrm{Me}, \mathrm{R}_{2}=\mathrm{H}$ : isoliensinine (3)

Fig. 1 Chemical structures of liensinine, neferine, and isoliensinine. 
In the present study, the capacity and possible mechanism of liensinine, neferine, and isoliensinine to inhibit microglial activation induced by LPS were investigated.

\section{Materials and methods}

\subsection{Cell culture and drug treatment}

Primary microglial cells were prepared from the cortex of newborn Kunming mice (Laboratory Animal Center, China Medical University). ${ }^{16}$ All animal experiments were performed following the National Guidelines for Experimental Animal Welfare 78 (MOST, PR China, 2006), and were approved by the Animal Studies Committee of 79 Liaoning University.

Briefly, after the meninges and blood vessels of the mouse cortex were removed, cortical tissue was cut into small pieces and dissociated with $0.25 \%$ trypsin-EDTA (Gibco, GrandIsland, $\mathrm{NY}$, USA) at $37^{\circ} \mathrm{C}$ for $10 \mathrm{~min}$, and then the cell suspension was filtered through $50 \mu \mathrm{m}$ diameter nylon mesh. The cells were collected by centrifugation at $1000 \mathrm{rpm}$ for $5 \mathrm{~min}$, re-suspended in Dulbecco's modified Eagle's medium (DMEM, Hyclone, Logan, UT, USA) supplemented with 5\% fetal bovine serum (FBS, Gibco), $2 \mathrm{mmol} \mathrm{L}^{-1}$ glutamine, penicillin (100 $\mathrm{U} \mathrm{mL}^{-1}$ ), and streptomycin $\left(100 \mu \mathrm{g} \mathrm{mL}^{-1}\right)$, and then plated in culture flasks. Cells were incubated at $37{ }^{\circ} \mathrm{C}$ under a humidified atmosphere of $5 \% \mathrm{CO}_{2}$. After 11-14 days, the flasks were shaken by hand for $10 \mathrm{~min}$. The resulting cell suspension, rich in microglial cells, was placed in another flask in which the cells were adhered for $30 \mathrm{~min}$ at $37^{\circ} \mathrm{C}$. The purity of microglial cells obtained was $>95 \%$ as identified by immunocytochemistry using the CD11b monoclonal antibody (ImmunoTools, Friesoythe, Germany). ${ }^{17}$

Liensinine, neferine, and isoliensinine (purity > 98\%, Chengdu Mansite Pharmaceutical Co. Ltd, Chengdu, Sichuan, China) were initially dissolved in dimethyl sulfoxide (DMSO, Sigma-Aldrich, St. Louis, MO, USA), and then diluted with DMEM medium without serum. DMSO at the highest concentration possibly present in experimental conditions $(0.1 \%)$ was not toxic to the cells. Exponentially growing microglial cells were treated with liensinine, neferine, or isoliensinine $\left(0.1-10 \mu \mathrm{mol} \mathrm{L}^{-1}\right)$ in the presence or absence of LPS ( $1 \mu \mathrm{g} \mathrm{mL} \mathrm{m}^{-1}$, Sigma-Aldrich).

\subsection{Cell viability assay}

The cell viability was evaluated by the 3-4-5-dimethylthiazole-2-yl2,5-diphenyl-tetrazolium bromide (MTT) assay. Primary microglial cells were seeded at $4 \times 10^{4}$ cells per well in 96-well plates. After $24 \mathrm{~h}$ incubation, the cells were treated with liensinine, neferine, or isoliensinine $\left(0.1-10 \mu \mathrm{mol} \mathrm{L}^{-1}\right)$ in the presence or absence of LPS $\left(1 \mu \mathrm{g} \mathrm{mL} \mathrm{g}^{-1}\right)$ for $48 \mathrm{~h}$. The medium was then removed and the cells were incubated with $0.25 \mathrm{mg} \mathrm{mL}^{-1}$ MTT (Gibco) for $4 \mathrm{~h}$ at $37^{\circ} \mathrm{C}$. The formazan crystals were dissolved in dimethyl sulfoxide (DMSO), and the absorbance was measured at $490 \mathrm{~nm}$ by a microplate reader (TECAN, Switzerland).

\subsection{Nitrite assay}

As a measure of NO release, nitrite accumulation in cell culture supernatant fluids was measured using the Griess reagent. ${ }^{18}$
Microglial cells at a density of $4 \times 10^{4}$ cells per well were seeded in 96-well plates for $24 \mathrm{~h}$ and incubated with liensinine, neferine, or isoliensinine $\left(0.1-10 \mu \mathrm{mol} \mathrm{L}^{-1}\right)$ in the presence or absence of LPS $\left(1 \mu \mathrm{g} \mathrm{mL} \mathrm{m}^{-1}\right)$ for $48 \mathrm{~h}$. Fifty microliters of culture supernatant fluids was mixed with an equal volume of the Griess reagent. The Griess reagent was made by a $1: 1$ mixture of $1 \%$ sulfanilamide in $5 \%$ phosphoric acid and $0.1 \%$ naphthylethylenediamine dihydrochloride in distilled water. The absorbance of the mixture was measured at $540 \mathrm{~nm}$ by the microplate reader. The amount of nitrite was calculated with reference to a sodium nitrite standard curve.

\subsection{NO-scavenging activity assay}

The NO-scavenging effects of three bisbenzylisoquinoline alkaloids $\left(0.1-10 \mu \mathrm{mol} \mathrm{L}^{-1}\right)$ were assessed according to the previous method. ${ }^{18}$ Sodium nitroprusside (SNP, $2.5 \mathrm{mmol} \mathrm{L}^{-1}$ ) was incubated alone or combined with various concentrations of liensinine, neferine, or isoliensinine. SNP is an inorganic substance where $\mathrm{NO}$ is found as $\mathrm{NO}^{+}$, and being exposed to light is necessary for the generation of NO. Therefore, the mixtures were incubated in light at room temperature for $60 \mathrm{~min}$, and nitrite levels were detected by the Griess reaction.

\subsection{Western blot analysis}

Microglial cells cultured in culture flasks were treated with liensinine, neferine, or isoliensinine $\left(1-10 \mu \mathrm{mol} \mathrm{L}^{-1}\right)$ in the presence of LPS $\left(1 \mu \mathrm{g} \mathrm{mL}{ }^{-1}\right)$. The cells were washed twice with ice-cold phosphate-buffered saline (PBS) and lysed for $30 \mathrm{~min}$ with radioimmunoprecipitation assay (RIPA) lysis buffer (Beyotime, Shanghai, China) supplemented with $1 \mathrm{mmol} \mathrm{L}^{-1}$ phenylmethylsulfonyl fluoride (PMSF) immediately before use. Concentration of protein in the supernatant fluids of the lysate was determined by the BCA assay (CWbiotech, Beijing, China) following the manufacturer's protocol. Equal amounts of protein were separated by electrophoresis and then the gel was transferred onto polyvinylidene fluoride membrane (PVDF, CWbiotech). The PVDF membranes were blocked in 5\% skimmed milk for $1 \mathrm{~h}$ at room temperature and then incubated overnight with primary antibodies against iNOS, I $\mathrm{B} \alpha$, phosphorylated I $\mathrm{K} \mathrm{B} \alpha(1: 1000$, all from Cell Signaling Technology, Danvers, MA), and $\beta$-actin $(1: 1000$, Proteintech Group, Wuhan, China), followed by horseradish peroxidase (HRP) conjugated secondary antibodies (Santa Cruz Biotechnology, Santa Cruz, CA, USA). The protein of interest was detected by enhanced chemiluminescence (ECL) reagents (Tanon, Shainghai, China) and visualized with a Tanon 5200 Multi Chemiluminescent System (Tanon, Shanghai, China). The relative values for each protein were normalized to $\beta$-actin.

\subsection{Reverse transcription polymerase chain reaction (RT- PCR) analysis}

Microglial cells were placed in 6-well plates and incubated with liensinine, neferine, or isoliensinine $\left(1-10 \mu \mathrm{mol} \mathrm{L}^{-1}\right)$ in the presence of LPS $\left(1 \mu \mathrm{g} \mathrm{mL}{ }^{-1}\right)$ for $24 \mathrm{~h}$. Total RNA was extracted with RNAiso plus (TaKaRa Bio Inc., Dalian, China) according to the manufacturer's protocol. The concentrations of total RNA 
A

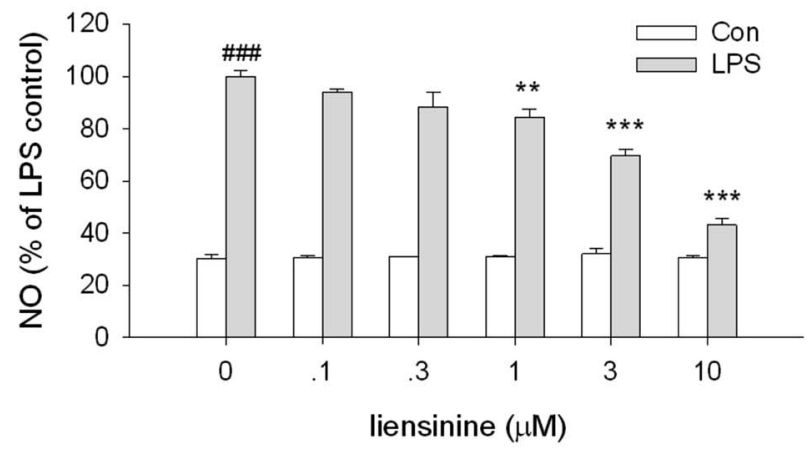

\section{B}

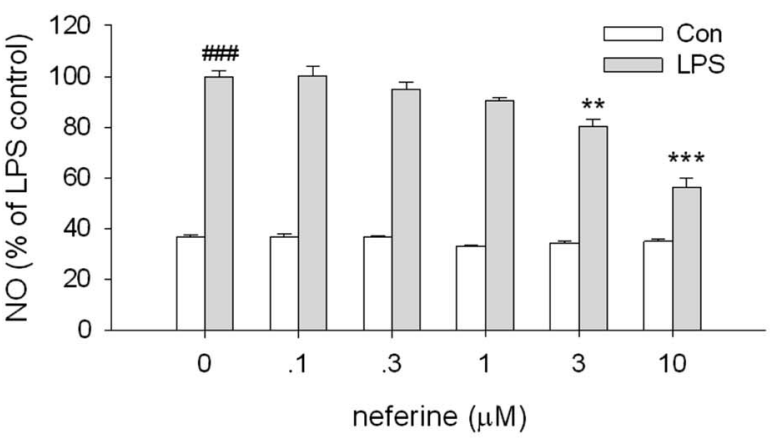

C

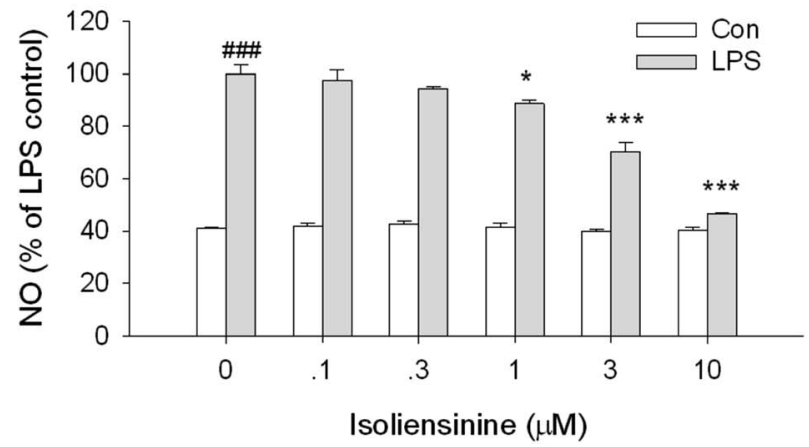

Fig. 2 Inhibitory effects of liensinine, neferine, and isoliensinine on NO production by unstimulated or LPS-activated microglial cells. Primary microglial cells were treated with liensinine $(A)$, neferine $(B)$, or isoliensinine (C) $\left(0.1-10 \mu \mathrm{mol} \mathrm{L}^{-1}\right)$ in the presence or absence of LPS $(1 \mu \mathrm{g}$ $\mathrm{mL}^{-1}$ ) for $48 \mathrm{~h}$. The results were expressed as the percentage values taking LPS treatment group as $100 \%$. Data were represented as mean \pm SEM of three separate experiments. ${ }^{\# \#} P<0.001$ as compared with the control group (cultured in medium alone), $* P<0.05, * * P<0.01$, $* * * P<0.001$ as compared with LPS alone group.

were measured using spectrophotometer. Total RNA $(1 \mu \mathrm{g})$ was reverse transcribed to complementary DNA (cDNA). In brief, one microgram of total RNA was mixed with oligo(dT) primer (TaKaRa Bio Inc.) and brought to a final volume of $6 \mu \mathrm{L}$ with RNase-free water. The RNA and primer mixtures were heated at $70{ }^{\circ} \mathrm{C}$ for $10 \mathrm{~min}$ and then immediately cooled on ice until the reverse transcription mixtures containing $5 \times \mathrm{M}-\mathrm{MLV}$ buffer, dNTP, M-MLV reverse transcriptase, and RNase-free water (all from TaKaRa Bio Inc.) were prepared. A total of $14 \mu \mathrm{L}$ of the reverse transcription mix and $6 \mu \mathrm{L}$ of total cellular RNA and
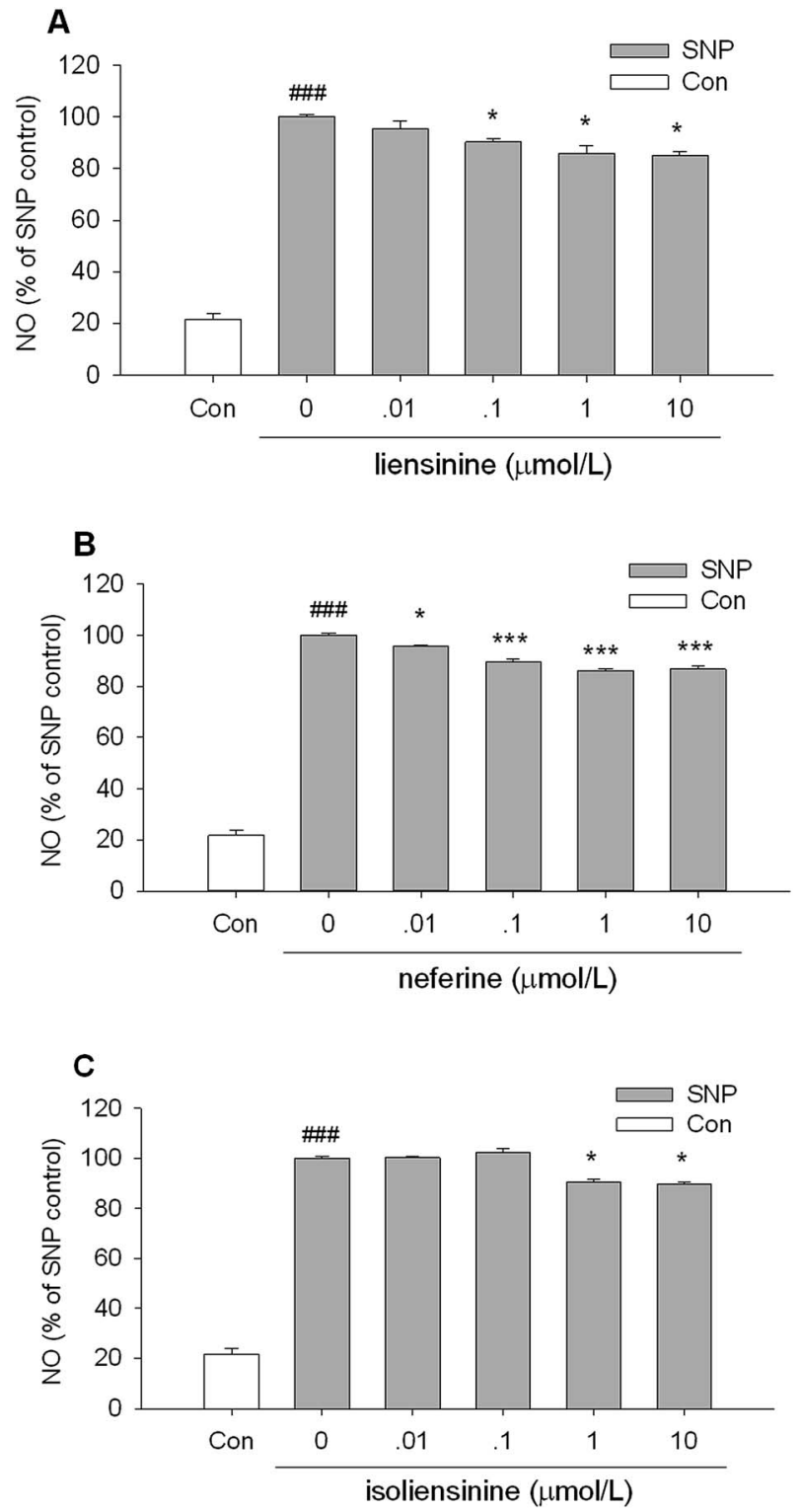

Fig. 3 Effects of liensinine, neferine, and isoliensinine on nitric oxidescavenging. SNP solution $\left(2.5 \mathrm{mmol} \mathrm{L}^{-1}\right)$ in PBS was incubated alone or with liensinine $(A)$, neferine $(B)$, or isoliensinine $(C)\left(0.01-10 \mu \mathrm{mol} \mathrm{L}^{-1}\right)$ in light at room temperature for $60 \mathrm{~min}$. The results were expressed as the percentage values taking the SNP group as $100 \%$. Data were represented as mean \pm SEM of three separate experiments. ${ }^{\# \#} P<$ 0.001 as compared with the control group (PBS alone), $* P<0.05, * * * P$ $<0.001$ as compared with the SNP group.

primer mixtures were incubated at $42{ }^{\circ} \mathrm{C}$ for $1 \mathrm{~h}$, followed by heating at $70{ }^{\circ} \mathrm{C}$ for $15 \mathrm{~min}$. The cDNA was then amplified by PCR using primers specific for the genes of GAPDH and iNOS: GAPDH forward, 5'-AGT GGC AAA GTG GAG ATT GTT G- $3^{\prime}$; GAPDH reverse, $5^{\prime}$-CAG TCT TCT GGG TGG CAG TGA T- $3^{\prime}$; iNOS forward, $5^{\prime}$-GAC AAG CTG CAT GTG ACA TC- $3^{\prime}$; iNOS reverse, $5^{\prime}$ GCT GGT AGG TTC CTG TTG TT- $3^{\prime}$. The following conditions of PCR reactions were applied: GAPDH, 28 cycles of denaturation at $94{ }^{\circ} \mathrm{C}$ for $30 \mathrm{~s}$, annealing at $60{ }^{\circ} \mathrm{C}$ for $30 \mathrm{~s}$, and extension at $72{ }^{\circ} \mathrm{C}$ for $30 \mathrm{~s}$; iNOS, 30 cycles of denaturation at $94{ }^{\circ} \mathrm{C}$ for $30 \mathrm{~s}$, 
A

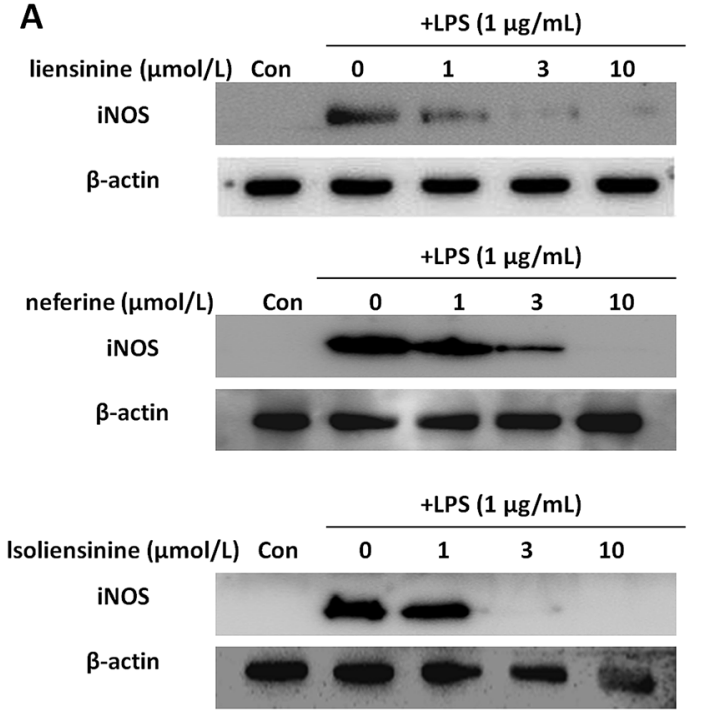

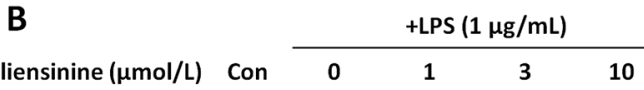

iNOS

GAPDH
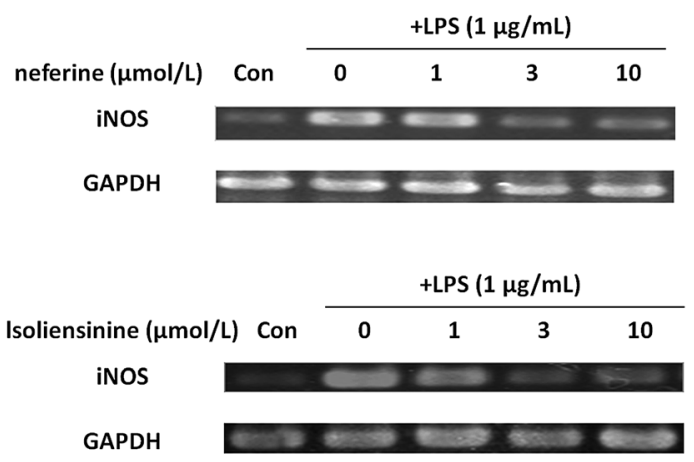

Fig. 4 Inhibitory effects of liensinine, neferine, and isoliensinine on LPS-induced expression of iNOS protein and mRNA in microglial cells. Microglial cells were treated with liensinine, neferine, or isoliensinine $\left(1-10 \mu \mathrm{mol} \mathrm{L}{ }^{-1}\right)$ in the presence of LPS $\left(1 \mu \mathrm{g} \mathrm{mL}{ }^{-1}\right)$ for $24 \mathrm{~h}$. (A) The expression of iNOS protein was analyzed by western blot. (B) The expression of iNOS mRNA was detected by RT-PCR.
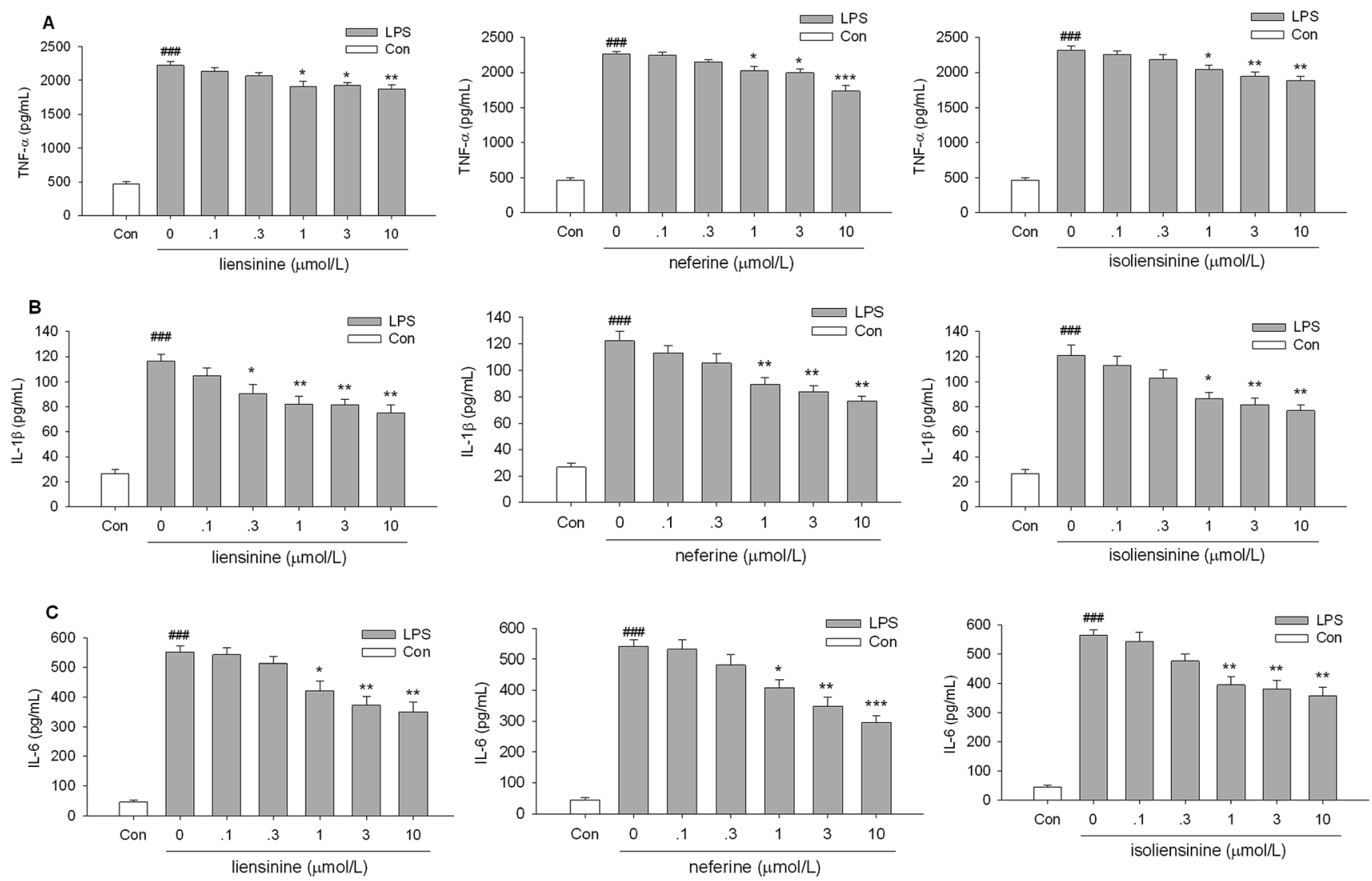

Fig. 5 Inhibitory effects of liensinine, neferine, and isoliensinine on TNF- $\alpha$, IL-1 $\beta$, and IL- 6 release by LPS-activated microglial cells. Microglial cells were treated with liensinine, neferine, or isoliensinine in the presence of LPS $\left(1 \mu \mathrm{g} \mathrm{mL}^{-1}\right)$. After incubation for $1 \mathrm{~h}$, the levels of TNF- $\alpha(A)$ in the supernatant fluids were measured. After incubation for $4 \mathrm{~h}$, the levels of IL-1 $\mathrm{B}(\mathrm{B})$ and IL- $6(\mathrm{C})$ in the supernatant fluids were measured. Data were represented as mean \pm SEM of three separate experiments. ${ }^{\# \#} P<0.001$ as compared with the control group, $* P<0.05, * * P<0.01, * * * P<$ 0.001 as compared with LPS alone group. 
annealing at $58{ }^{\circ} \mathrm{C}$ for $30 \mathrm{~s}$, and extension at $72{ }^{\circ} \mathrm{C}$ for $30 \mathrm{~min}$. PCR products were separated in $1.2 \%$ agarose gels, visualized by staining with ethidium bromide, and yielded the expected amplicons of 480 and 293 bp, respectively.

\subsection{Cytokine level measurement}

Supernatant fluids of LPS-activated microglial cells incubated with or without liensinine, neferine, or isoliensinine (0.1-10 $\mu \mathrm{mol} \mathrm{L}{ }^{-1}$ ) were collected to quantitate the production of TNF- $\alpha$, IL-1 $\beta$, and IL- 6 using the enzyme-linked immunosorbent assay (ELISA) kits according to the manufacturer's instructions (R\&D Systems, Minneapolis, MN, USA).

\subsection{Intracellular ROS assay}

The intracellular reactive oxygen species (ROS) was detected using $2^{\prime}, 7^{\prime}$-dichlorodihydrofluororescein diacetate (DCFH-DA, Sigma-Aldrich). ${ }^{19}$ DCFH-DA was dissolved in methanol at $10 \mathrm{mmol} \mathrm{L}^{-1}$ and diluted 500-fold in PBS to give final concentration at $20 \mu \mathrm{mol} \mathrm{L}{ }^{-1}$. Microglial cells were seeded in 6-well plates for $24 \mathrm{~h}$ and then treated with liensinine, neferine, or isoliensininein ( 1 and $\left.3 \mu \mathrm{mol} \mathrm{L}{ }^{-1}\right)$ in the presence of LPS $(1 \mu \mathrm{g}$ $\mathrm{mL}^{-1}$ ) for $12 \mathrm{~h}$. The cells were exposed to DCFH-DA for $30 \mathrm{~min}$ at $37{ }^{\circ} \mathrm{C}$. After washing three times with PBS, the cells were resuspended in the PBS. Intracellular ROS levels were analysised by a FACScan flow cytometer (Becton-Dickinson, San Jose, CA, USA). The results are presented as mean fluorescence intensity of the population.

\subsection{DPPH scavenging activity assay}

The DPPH free radical scavenging effects of three compounds were determined according to the previous method. ${ }^{16}$ 2,2Diphenyl-1-picrylhydrazyl (DPPH, Sigma-Aldrich) was dissolved in $100 \%$ ethanol at a final concentration of $100 \mu \mathrm{mol} \mathrm{L}{ }^{-1}$. The mixture was then shaken in the dark for $10 \mathrm{~min}$. Liensinine, neferine, or isoliensininein $(500 \mu \mathrm{L}$ each $)$ was added to $500 \mu \mathrm{L}$ of DPPH free radical solution. After incubation in the dark at room temperature for $30 \mathrm{~min}$, the absorbance at $517 \mathrm{~nm}$ was measured using the microplate reader.

\subsection{OH scavenging activity assay}

Hydroxyl radical $(\cdot \mathrm{OH})$ scavenging effects of three bisbenzylisoquinoline alkaloids were performed as previously described with slight modifications. ${ }^{20}$ Liensinine, neferine, or isoliensininein was added to the mixture containing $2 \mathrm{mmol} \mathrm{L}^{-1}$ $\mathrm{FeSO}_{4}$ and $0.8 \mathrm{mmol} \mathrm{L} \mathrm{L}_{2} \mathrm{O}_{2}$. After standing at room temperature for $10 \mathrm{~min}$, the reaction was initiated by adding the salicylic acid solution $\left(1.5 \mathrm{mmol} \mathrm{L}^{-1}\right)$. Reaction mixture was incubated at $37{ }^{\circ} \mathrm{C}$ for $30 \mathrm{~min}$. The absorbance at $510 \mathrm{~nm}$ was detected using the microplate reader.

\subsection{ONOO $^{-}$scavenging activity assay}

The peroxynitrite $\left(\mathrm{ONOO}^{-}\right)$scavenging activity was assayed according to the reported method with some modifications. ${ }^{21}$ The synthesis reaction was performed at $4{ }^{\circ} \mathrm{C}$. Five milliliters of solution containing $0.08 \mathrm{~mL}$ of $\mathrm{H}_{2} \mathrm{SO}_{4}(96 \%), 0.3 \mathrm{~mL}$ of $\mathrm{H}_{2} \mathrm{O}_{2}$
(30\%), and $4.62 \mathrm{~mL}$ of distilled water was mixed with $5 \mathrm{~mL}$ of $0.6 \mathrm{~mol} \mathrm{~L}^{-1} \mathrm{NaNO}_{2}$ at $4{ }^{\circ} \mathrm{C}$. Then, $5 \mathrm{~mL}$ of $1.25 \mathrm{~mol} \mathrm{~L}^{-1}$ ice cold $\mathrm{NaOH}$ was immediately added to quench the reaction. Residual $\mathrm{H}_{2} \mathrm{O}_{2}$ was removed by using $0.08 \mathrm{~g} \mathrm{MnO}_{2}$ (solid powder) and the reaction mixture was left overnight at $-20{ }^{\circ} \mathrm{C}$ in the dark. The absorbance of the complex was detected at $302 \mathrm{~nm}$ using a UV spectrophotometer. The concentration of $\mathrm{ONOO}^{-}$was calculated according to Bouguer-Lambert-Beer law. The L-tyrosine $\left(75 \mu \mathrm{mol} \mathrm{L}^{-1}\right)$ was mixed with $\mathrm{ONOO}^{-}$solution $\left(96 \mu \mathrm{mol} \mathrm{L}{ }^{-1}\right)$, and then liensinine, neferine, or isoliensinine $\left(0.1-10 \mu \mathrm{mol} \mathrm{L}^{-1}\right)$ was added to the mixture. After incubating at $37^{\circ} \mathrm{C}$ in the water bath for $30 \mathrm{~min}$, the absorbance was detected at $428 \mathrm{~nm}$ using the microplate reader.

\subsection{Statistical analysis}

Results are expressed as mean \pm SEM for at least three independent experiments. Statistical analysis was performed using SPSS 19.0 software. The data were analyzed by one-way analysis of variance (ANOVA) followed by Dunnett's $t$-test. Significance between two groups was analyzed by $t$-test.

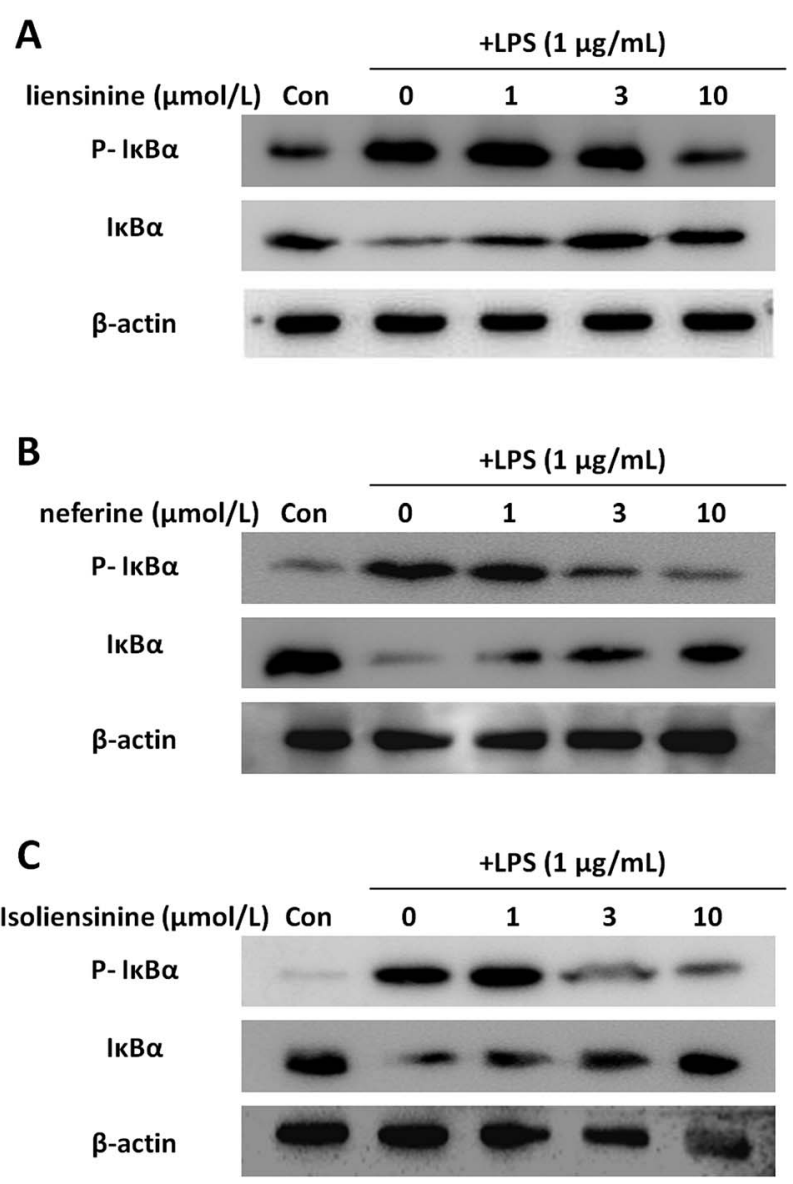

Fig. 6 Inhibitory effects of liensinine, neferine, and isoliensinine on I $\mathrm{B} \alpha \alpha$ phosphorylation and degradation induced by LPS in microglial cells. Microglial cells were treated with liensinine (A), neferine (B), or isoliensinine (C) in the presence of LPS $\left(1 \mu \mathrm{g} \mathrm{mL}^{-1}\right)$ for $30 \mathrm{~min}$. Total protein was subjected to $10 \%$ SDS-PAGE followed by western blotting using $I_{\kappa} B \alpha$ and phosphorylated $I_{\kappa} B \alpha$ antibodies. 


\section{Results and discussion}

\subsection{Inhibitory effects of liensinine, neferine, and isoliensinine on LPS-induced NO production}

MTT assay, a kind of indirect cell viability measurement method, is based upon the capability of mitochondrial succinate dehydrogenase in viable cells to deoxygenize MTT to insoluble purple formazan products. In order to avoid the possible effects of reduced viability on NO and cytokine release, the effects of three bisbenzylisoquinoline alkaloids on the cell viability were studied at first. Co-treatment of either unstimulated or stimulated primary microglia with liensinine, neferine, or isoliensinine $\left(0.1-10 \mu \mathrm{mol} \mathrm{L}^{-1}\right)$ did not affect the viability of microglial cells (data not shown). The results indicate that the effects of three alkaloids on microglial cells were unlikely due to the toxicity. However, it is widely known that most of alkaloids have a high toxicity in vivo, further studies are required in order to understand the safety of three alkaloids in vivo.

Nitric oxide (NO), synthesized by a conversion of L-arginine to L-citrulline by iNOS, is an important mediator and its generation is a crucial procedure in the activation of microglia. ${ }^{22}$ A significant enhancement in the expression of iNOS in microglial cells leads to surplus production of NO, which associated with various neurodegenerative diseases. ${ }^{23}$ In this study, the production of NO by LPS-stimulated microglial cells was examined. As shown in Fig. 2, LPS caused a substantial increase in NO production compared to the control group $(P<0.001)$. Three bisbenzylisoquinoline alkaloids inhibited LPS-induced NO production in a concentration-dependent manner, with the $\mathrm{IC}_{50}$ values of 4.4, 6.9, and $3.8 \mu \mathrm{mol} \mathrm{L}^{-1}$, respectively. The results presented here indicated that liensinine and isoliensinine had more potent inhibitory activity on NO production than neferine. As a bisbenzylisoquinoline alkaloid originated from the dried root of one Chinese herb of Radix Stephania tetrandra, tetrandrine has been proved to exert the anti-inflammatory effect by inhibiting the production of NO in activated microglial cells induced by LPS or Amyloid- $\beta(A \beta) .{ }^{24,25}$ In this study, the effect of tetrandrine on NO production in activated microglia was also observed. The results showed that liensinine, neferine, and isoliensinine had more potential inhibitory effect on NO production than that of tetrandrine $\left(\mathrm{IC}_{50}=7.9 \mu \mathrm{mol} \mathrm{L} \mathrm{L}^{-1}\right.$; data not shown). Furthermore, treatment of unstimulated cells with three alkaloids $\left(0.1-10 \mu \mathrm{mol} \mathrm{L}^{-1}\right)$ did not result in any change of NO production.
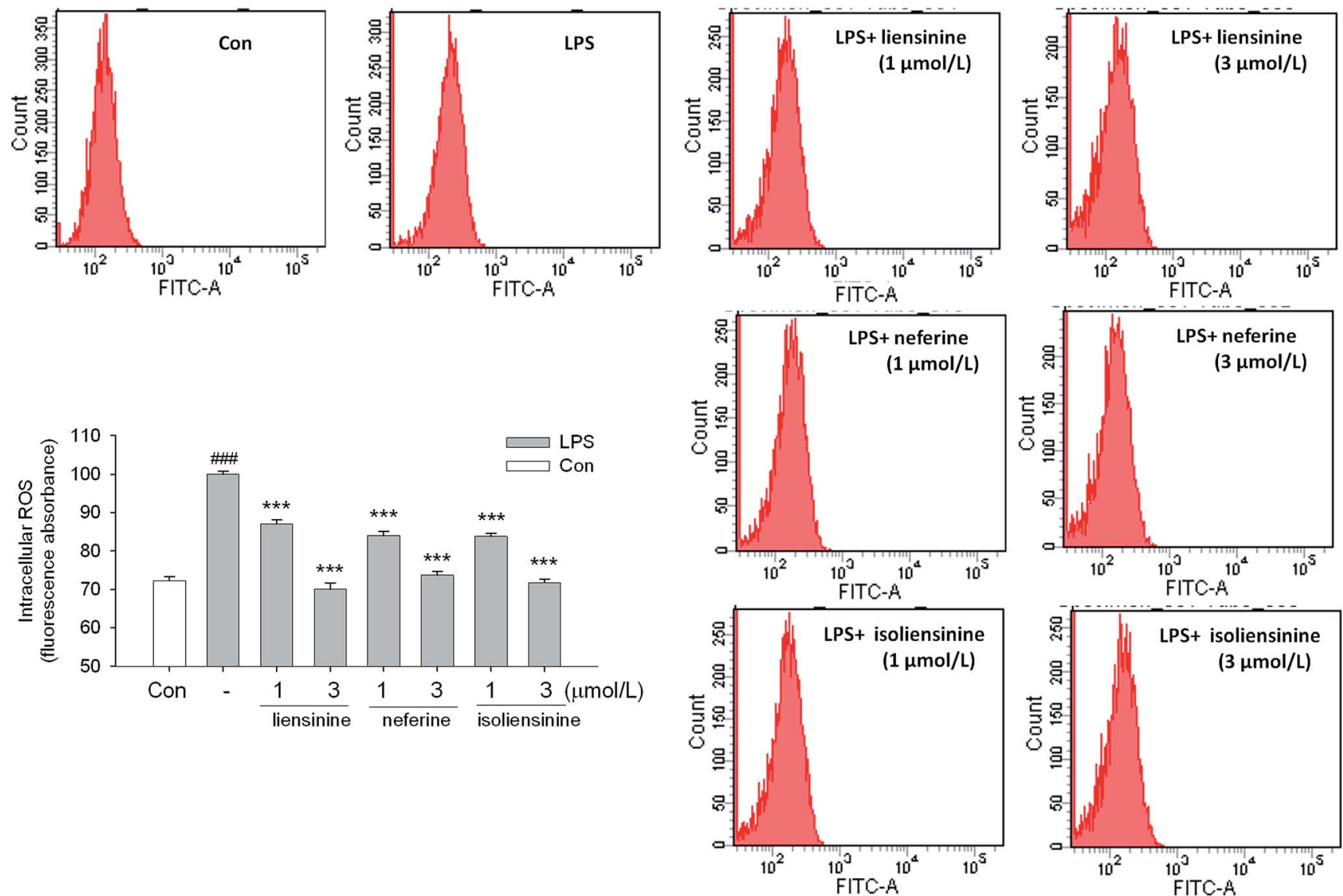

Fig. 7 Inhibitory effects of liensinine, neferine, and isoliensinine on LPS-induced ROS production in microglial cells. Microglial cells were treated with liensinine, neferine, or isoliensinine $(1$ and $3 \mu \mathrm{M})$ in the presence of LPS $\left(1 \mu \mathrm{g} \mathrm{mL}^{-1}\right)$ for $12 \mathrm{~h}$. Intracellular ROS were determined by DCFH oxidation. The results were expressed as the percentage values taking LPS treatment group as $100 \%$. Data were represented as mean \pm SEM of three separate experiments. ${ }^{\# \# ~} P<0.001$ as compared with the control group, $* * * P<0.001$ as compared with LPS alone group. 
3.2 NO-scavenging effects of liensinine, neferine, and isoliensinine

Then, the NO-scavenging activity of three bisbenzylisoquinoline alkaloids was measured using SNP as a NO donor to explore whether the suppressive effects of NO release were attributed to direct NO-scavenging activity. ${ }^{26,27}$

As shown in Fig. 3, when a solution of $2.5 \mathrm{mmol} \mathrm{L}^{-1} \mathrm{SNP}$ was incubated in light at room temperature for $1 \mathrm{~h}$, it generated nitrite which was decreased by the presence of liensinine (Fig. 3A), neferine (Fig. 3B), or isoliensinine (Fig. 3C) in a concentration-dependent manner. Three bisbenzylisoquinoline alkaloids displayed low direct NOscavenging activity and might act as the potent NO inhibitors in microglial cells. The NO-scavenging activity of neferine was consistent with the previous report. ${ }^{13}$ Moreover, the direct NO-scavenging effects of three alkaloids are weaker than that of NO production by LPS-activated microglial cells (Fig. 2), which indicated that the direct NO-scavenging effects are likely to be one of the mechanisms of these alkaloids to decrease the NO level in culture supernatant fluids of LPSactivated microglial cells.

\subsection{Effects of liensinine, neferine, and isoliensinine on LPS- induced expression of iNOS protein and mRNA}

In order to evaluate whether the suppression of three alkaloids on NO generation was related to the regulation of iNOS induction, we detected iNOS protein and mRNA expression in LPS-activated microglia. As shown in Fig. 4, the levels of iNOS protein and mRNA expression in microglial cells were markedly up-regulated after LPS stimulation for $24 \mathrm{~h}$. Co-incubation of the microglial cells with LPS plus liensinine, neferine, or isoliensinine $\left(1-10 \mu \mathrm{mol} \mathrm{L}^{-1}\right)$, the expression of iNOS in the cells was concentration-dependently suppressed at both the protein levels (Fig. 4A) and mRNA levels (Fig. 4B). Moreover, the mRNA expression levels of iNOS followed the same trends as those of the protein. Therefore, the decrease of NO production may be attributed to the inhibition of iNOS mRNA transcription followed by reduced iNOS protein production, and direct NO-scavenging effects mentioned above. In addition, liensinine and isoliensinine were found to have more potent inhibitory effects on iNOS protein production than neferine.

\subsection{Inhibitory effects of liensinine, neferine, and isoliensinine on LPS-induced TNF- $\alpha$, IL-1 $\beta$, and IL-6 release}

TNF- $\alpha$, IL-1 $\beta$, and IL-6 are key inflammatory cytokines, which have been verified to be responsible for inflammation accompanied by the brain damage. ${ }^{\mathbf{2 8 , 2 9}}$ The levels of three activation-related cytokines (TNF- $\alpha$, IL-1 $\beta$, and IL-6) in cell culture supernatant fluids were measured by ELISA. Stimulation of microglial cells with LPS led to an increase in TNF- $\alpha$, IL$1 \beta$, and IL- 6 levels in the culture media. Liensinine, neferine, and isoliensinine could significantly inhibit LPS-induced TNF$\alpha$ (Fig. 5A), IL-1 $\beta$ (Fig. 5B), or IL-6 release (Fig. 5C) at the concentrations of 1,3 , and $10 \mu \mathrm{mol} \mathrm{L}^{-1}$. These results further
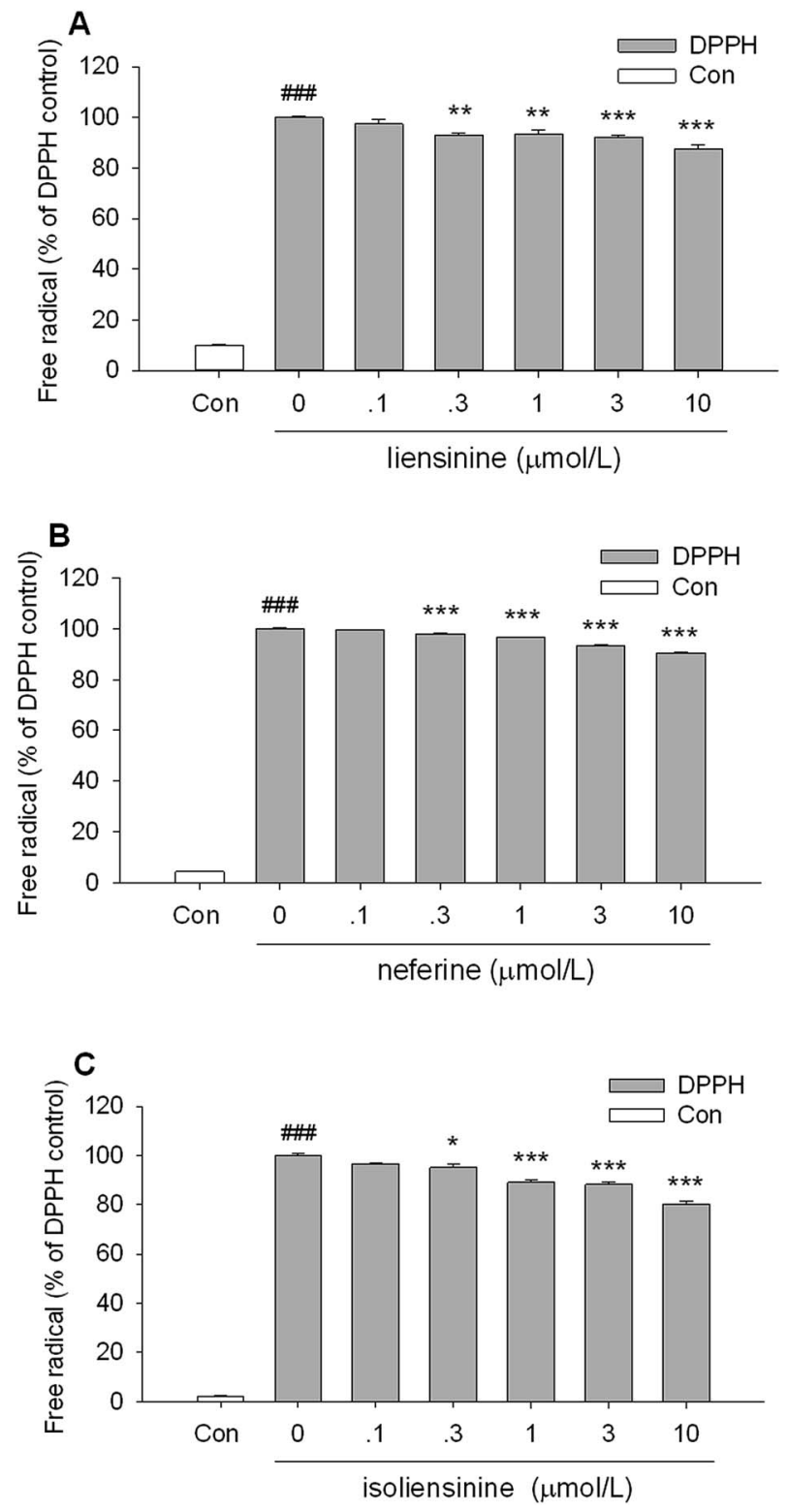

Fig. 8 DPPH free radical scavenging activity of liensinine, neferine, and isoliensinine. The results were expressed as the percentage values taking only DPPH group as $100 \%$. Data were represented as mean \pm SEM of three separate experiments. ${ }^{\# \# \# ~} P<0.001$ as compared with the control group (100\% ethanol alone), $* P<0.05, * * P<0.01, * * * P<$ 0.001 as compared with only DPPH group.

confirmed the inhibitory effects of three alkaloids on microglial activation.

However, it should be noticed that three alkaloids were more effective on NO production than on TNF- $\alpha$, IL-1 $\beta$, and IL-6 release, which suggested that the regulatory mechanisms of three alkaloids on TNF- $\alpha$, IL-1 $\beta$, IL-6, and NO production may be at least partly different. Liensinine, neferine, and isoliensinine have also been demonstrated to blockade of $\mathrm{Ca}^{2+}$ influx. ${ }^{30-32}$ Whether the $\mathrm{Ca}^{2+}$ signaling pathway contributes to the inhibition of NO and cytokines production by three alkaloids in LPS-activated microglia will 

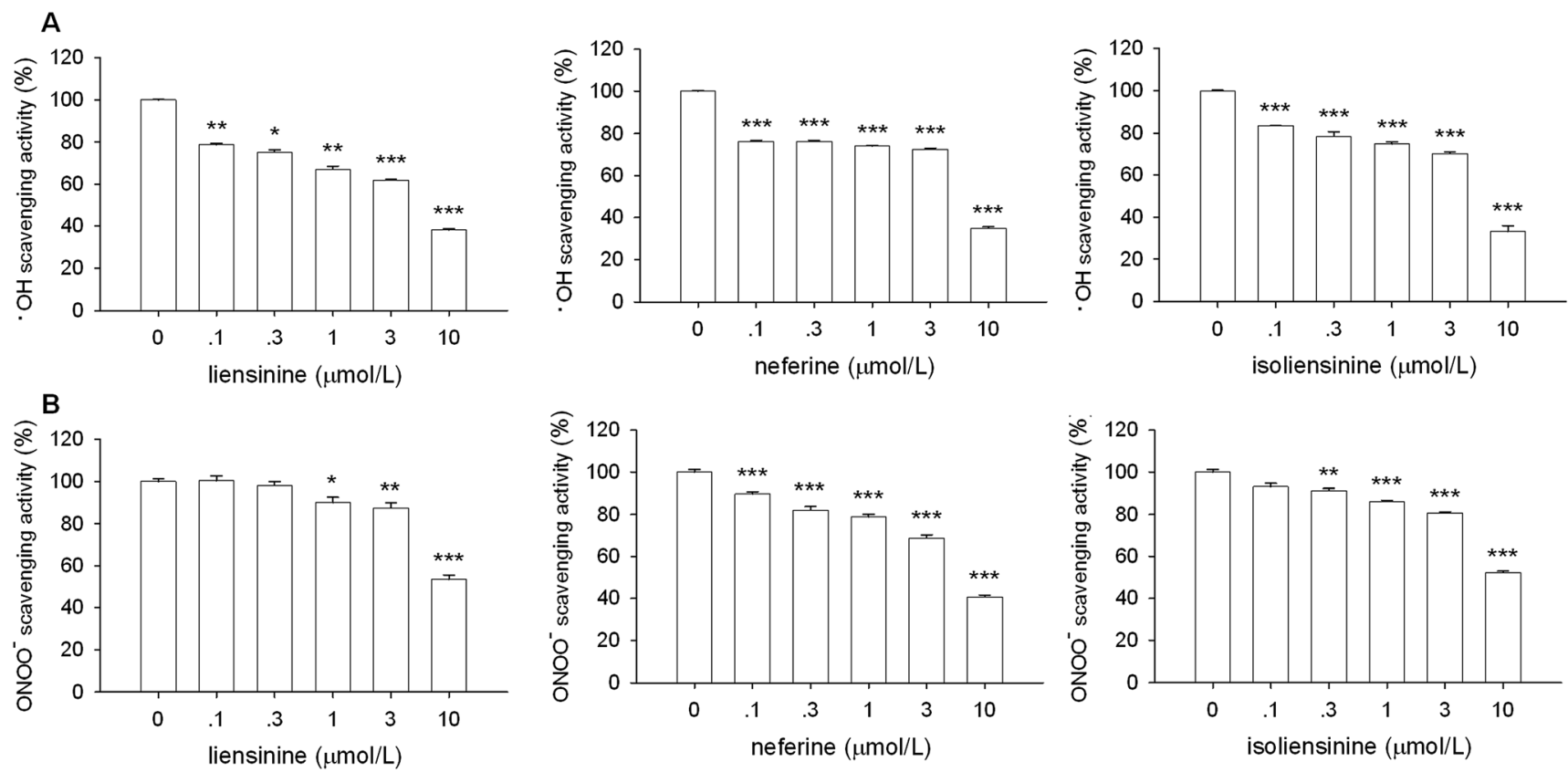

Fig. $9 \cdot \mathrm{OH}$ and $\mathrm{ONOO}^{-}$free radical scavenging activity of liensinine, neferine, and isoliensinine. The results were expressed as the percentage values taking model group as $100 \%$. Data were represented as mean $\pm \mathrm{SEM}$ of three separate experiments. $* P<0.05, * * P<0.01, * * * P<0.001$ as compared with model group.

be further investigated. The exact mechanism remains to be clarified.

\subsection{Inhibitory effects of liensinine, neferine, and isoliensinine on LPS-induced I $\mathrm{KB} \alpha$ phosphorylation and degradation}

NF- $\kappa \mathrm{B}$ is considered to be a major transcription factor in the regulation of the inflammatory cytokines and inducible enzymes, such as TNF- $\alpha$, IL-1 $\beta$, IL-6, and iNOS. ${ }^{33}$ In resting cells, NF- $\mathrm{\kappa B}$ is located in the cytoplasm as an inactive complex bound to its inhibitor, IкB. The activation of NF- $\kappa \mathrm{B}$ depends on phosphorylation, ubiquitination, and subsequent degra-

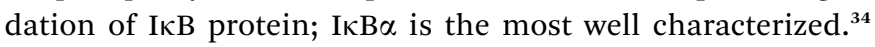
The liberated NF- $\kappa \mathrm{B}$ translocates to the nucleus and binds to the regulatory region in the promoter of specific genes, leading to their transcription. ${ }^{35}$ Isoliensinine has been found to intervene in NF- $\mathrm{\kappa B}$ activation in hepatocellular carcinoma cells. ${ }^{6,36}$ Neferine was shown to inhibit NF- $\mathrm{KB}$ activation and nuclear translocation in lung cancer cells, ${ }^{37}$ human rhabdomyosarcoma cells, ${ }^{38}$ vascular smooth muscle cells, ${ }^{39}$ and endothelial cells. ${ }^{40}$ However, the effects of liensinine, neferine, and isoliensinine on the NF- $\mathrm{KB}$ activation of microglial cells remain to be unclear.

In this study, the levels of $\mathrm{p}-\mathrm{I} \kappa \mathrm{B} \alpha$ were increased and the levels of $I \kappa B \alpha$ were decreased after LPS treatment, indicating I $\mathrm{B} \mathrm{\alpha} \alpha$ was prominently phosphorylated and degraded (Fig. 6). Liensinine (Fig. 6A), neferine (Fig. 6B), or isoliensinine (Fig. 6C) treatment resulted in the inhibition of LPS-induced phosphorylation and degradation of $\mathrm{I} \kappa \mathrm{B} \alpha$ protein. These findings demonstrated that three alkaloids exerted their inhibitory effects on LPS-induced microglial activation by blocking the NF-KB signaling pathway.

\subsection{Inhibitory effects of liensinine, neferine, and isoliensinine on LPS-induced ROS production}

Activated microglial cells produce high levels of ROS by activating NADPH oxidase (NOX), ${ }^{41,42}$ and ROS may be an early signal triggering the induction of inflammatory cytokines and participating in inflammatory signaling pathways. ${ }^{43}$ Moreover, intracellular redox changes induced by ROS augment NF- $\mathrm{B}$ activation through the phosphorylation and degradation of IKB via increasing Akt or IKK kinase activity. ${ }^{44}$ Thus, ROS/NF- $\mathrm{B}$ signaling pathway may play a pivotal role in LPS-activated microglial cells. ${ }^{45}$

In our study, the results showed that liensinine, neferine, and isoliensinine $\left(1\right.$ and $\left.3 \mu \mathrm{mol} \mathrm{L}^{-1}\right)$ effectively suppressed intracellular ROS production in LPS-stimulated microglial cells, which suggested that they are potent antioxidants (Fig. 7).

\subsection{DPPH, $\cdot \mathrm{OH}$, and $\mathrm{ONOO}^{-}$scavenging effects of} liensinine, neferine, and isoliensinine

As shown in Fig. 8, all of the three bisbenzylisoquinoline alkaloids showed low direct scavenging effects on the artificial model radical DPPH in a cell free assay. The scavenging effects of three alkaloids on DPPH radicals appeared at the concentrations of $0.3-10 \mu \mathrm{mol} \mathrm{L}^{-1}$. The DPPH free radicals scavenging effects of three alkaloids are weaker than that of intracellular ROS production by LPS-activated microglial cells (Fig. 7), which suggested that the free radicals scavenging effects are likely to be one of the mechanisms of these alkaloids to decrease the intracellular ROS level in LPS-activated microglial cells. 
As shown in Fig. 9A, liensinine, neferine, and isoliensinine showed potent scavenging activities against $\cdot \mathrm{OH}$ radicals as compared with the model group, with the $\mathrm{IC}_{50}$ values of 5.4, 6.9, and $6.6 \mu \mathrm{mol} \mathrm{L}^{-1}$, respectively. In addition, liensinine, neferine, and isoliensinine exhibited significant scavenging activities against $\mathrm{ONOO}^{-}$in a concentration-dependent manner, with respective $\mathrm{IC}_{50}$ values of $10.5,7.8$, and $10.3 \mu \mathrm{mol} \mathrm{L}^{-1}$ (Fig. 9B).

Three alkaloids exerted scavenging activities against DPPH, $\cdot \mathrm{OH}$, and $\mathrm{ONOO}^{-}$radicals. These results suggest that liensinine, neferine, and isoliensinine may suppress NF- $\kappa \mathrm{B}$ signaling at least partly by scavenging the free radicals and inhibiting the ROS generation in LPS-activated microglial cells.

\section{Conclusion}

In summary, these findings demonstrate for the first time that liensinine, neferine and isoliensinine exert anti-neuroinflammatory activity by suppressing the production of NO, TNF- $\alpha$, IL-1 $\beta$, and IL-6 in LPS-activated microglial cells. Moreover, three bisbenzylisoquinoline alkaloids inhibit the phosphorylation and degradation of $\mathrm{I} \kappa \mathrm{B} \alpha$ induced by LPS in microglial cells, and this effect is mediated at least in part by inhibiting the intracellular ROS generation and scavenging the free radicals.

Our results revealed the key roles of liensinine, neferine and isoliensinine in the anti-neuroinflammatory effects of the embryo of Nelumbo nucifera seeds and open a new avenue to understand the potential of this health food in the treatment of neurodegenerative diseases accompanied by microglial activation.

\section{Acknowledgements}

This study was supported by the National Natural Science Foundation of China (No. 81503085 and No. 31371085) and the Scientific Research Starting Foundation for Doctor of Liaoning province of China (No. 201601097).

\section{References}

1 F. Gonzalez-Scarano and G. Baltuch, Microglia as mediators of inflammatory and degenerative diseases, Annu. Rev. Neurosci., 1999, 22, 219-240.

2 X. Hu, A. K. Liou, R. K. Leak, M. Xu, C. An, J. Suenaga, Y. Shi, Y. Gao, P. Zheng and J. Chen, Neurobiology of microglial action in CNS injuries: receptor-mediated signaling mechanisms and functional roles, Prog. Neurobiol., 2014, 119-120, 60-84.

3 V. H. Perry and C. Holmes, Microglial priming in neurodegenerative disease, Nat. Rev. Neurol., 2014, 10, 217224.

4 S. Liu, B. Wang, X. Z. Li, L. F. Qi and Y. Z. Liang, Preparative separation and purification of liensinine, isoliensinine and neferine from seed embryo of Nelumbo nucifera GAERTN using high-speed counter-current chromatography, J. Sep. Sci., 2009, 32, 2476-2481.

5 P. Poornima, C. F. Weng and V. V. Padma, Neferine from Nelumbo nucifera induces autophagy through the inhibition of PI3K/Akt/mTOR pathway and ROS hyper generation in A549 cells, Food Chem., 2013, 141, 3598-3605.

6 G. Shu, L. Yue, W. Zhao, C. Xu, J. Yang, S. Wang and X. Yang, Isoliensinine, a bioactive alkaloid derived from embryos of Nelumbo nucifera, induces hepatocellular carcinoma cell apoptosis through suppression of NF-кB signaling, J. Agric. Food Chem., 2015, 63, 8793-8803.

7 J. Zhou, G. Li, Y. Zheng, H. M. Shen, X. Hu, Q. L. Ming, C. Huang, P. Li and N. Gao, A novel autophagy/mitophagy inhibitor liensinine sensitizes breast cancer cells to chemotherapy through DNM1L-mediated mitochondrial fission, Autophagy, 2015, 11, 1259-1279.

8 U. Grienke, C. E. Mair, P. Saxena, I. Baburin, O. Scheel, M. Ganzera, D. Schuster, S. Hering and J. M. Rollinger, Human ether-à-go-go related gene (hERG) channel blocking aporphine alkaloids from lotus leaves and their quantitative analysis in dietary weight loss supplements, $J$. Agric. Food Chem., 2015, 63, 5634-5639.

9 C. Wang, Y. F. Chen, X. Q. Quan, H. Wang, R. Zhang, J. H. Xiao, J. L. Wang, C. T. Zhang, J. Z. Xiang and Q. Tang, Effects of neferine on Kv4.3 channels expressed in HEK293 cells and ex vivo electrophysiology of rabbit hearts, Acta Pharmacol. Sin., 2015, 36, 1451-1461.

10 L. Zheng, Y. Cao, S. Liu, Z. Peng and S. Zhang, Neferine inhibits angiotensin II-induced rat aortic smooth muscle cell proliferation predominantly by downregulating fractalkine gene expression, Exp. Ther. Med., 2014, 8, 15451550.

11 H. A. Jung, S. E. Jin, R. J. Choi, D. H. Kim, Y. S. Kim, J. H. Ryu, D. W. Kim, Y. K. Son, J. J. Park and J. S. Choi, Anti-amnesic activity of neferine with antioxidant and anti-inflammatory capacities, as well as inhibition of ChEs and BACE1, Life Sci., 2010, 87, 420-430.

12 Y. Sugimoto, S. Furutani, A. Itoh, T. Tanahashi, H. Nakajima, H. Oshiro, S. Sun and J. Yamada, Effects of extracts and neferine from the embryo of Nelumbo nucifera seeds on the central nervous system, Phytomedicine, 2008, 15, 1117-1124.

13 Y. Sugimoto, K. Nishimura, A. Itoh, T. Tanahashi, H. Nakajima, H. Oshiro, S. Sun, T. Toda and J. Yamada, Serotonergic mechanisms are involved in antidepressantlike effects of bisbenzylisoquinolines liensinine and its analogs isolated from the embryo of Nelumbo nucifera Gaertner seeds in mice, J. Pharm. Pharmacol., 2015, 67, 1716-1722.

14 H. A. Jung, S. Karki, J. H. Kim and J. S. Choi, BACE1 and cholinesterase inhibitory activities of Nelumbo nucifera embryos, Arch. Pharmacal Res., 2015, 38, 1178-1187.

15 V. K. Wong, A. G. Wu, J. R. Wang, L. Liu and B. Y. Law, Neferine attenuates the protein level and toxicity of mutant huntingtin in PC-12 cells via induction of autophagy, Molecules, 2015, 20, 3496-3514.

16 X. L. Meng, J. Y. Yang, G. L. Chen, L. H. Wang, L. J. Zhang, S. Wang, J. Li and C. F. Wu, Effects of resveratrol and its derivatives on lipopolysaccharide-induced microglial activation and their structure-activity relationships, Chem.Biol. Interact., 2008, 174, 51-59. 
17 G. Wang, J. Zhang, W. Li, G. Xin, Y. Su, Y. Gao, H. Zhang, G. Lin, X. Jiao and K. Li, Apoptosis and proinflammatory cytokine responses of primary mouse microglia and astrocytes induced by human $\mathrm{H} 1 \mathrm{~N} 1$ and avian $\mathrm{H} 5 \mathrm{~N} 1$ influenza viruses, Cell. Mol. Immunol., 2008, 5, 113-120.

18 X. L. Meng, J. Y. Yang, G. L. Chen, L. J. Zhang, L. H. Wang, J. Li, J. M. Wang and C. F. Wu, RV09, a novel resveratrol analogue, inhibit NO and TNF- $\alpha$ production by LPSactivated microglia, Int. Immunopharmacol., 2008, 8, 10741082.

19 Y. Yu, J. R. Du, C. Y. Wang and Z. M. Qian, Protection against hydrogen peroxide-induced injury by Z-ligustilide in PC12 cells, Exp. Brain Res., 2008, 184, 307-312.

20 N. Smirnoff and Q. J. Cumbes, Hydroxyl radical scavenging activity of compatible solutes, Phytochemicals, 1989, 28, 1057-1060.

21 J. S. Beckman, T. W. Beckman, J. Chen, P. A. Marshall and B. A. Freeman, Apparent hydroxyl radical production by peroxynitrite: implications for endothelial injury from nitric oxide and superoxide, Proc. Natl. Acad. Sci. U. S. A., 1990, 87, 1620-1624.

22 H. Possel, H. Noack, J. Putzke, G. Wolf and H. Sies, Selective upregulation of inducible nitric oxide synthase (iNOS) by lipopolysaccharide (LPS) and cytokines in microglia: in vitro and in vivo studies, Glia, 2000, 32, 51-59.

23 J. J. Neher, U. Neniskyte, J. W. Zhao, A. Bal-Price, A. M. Tolkovsky and G. C. Brown, Inhibition of microglial phagocytosis is sufficient to prevent inflammatory neuronal death, J. Immunol., 2011, 186, 4973-4983.

24 F. Q. He, B. Y. Qiu, T. K. Li, Q. Xie, D. J. Cui, X. L. Huang and H. T. Gan, Tetrandrine suppresses amyloid- $\beta$-induced inflammatory cytokines by inhibiting NF- $\kappa \mathrm{B}$ pathway in murine BV2 microglial cells, Int. Immunopharmacol., 2011, 11, 1220-1225.

25 Y. Dang, Y. Xu, W. Wu, W. Li, Y. Sun, J. Yang, Y. Zhu and C. Zhang, Tetrandrine suppresses lipopolysaccharideinduced microglial activation by inhibiting NF- $\kappa \mathrm{B}$ and ERK signaling pathways in BV2 cells, PLoS One, 2014, 9, e102522.

26 Z. Hu, Y. Huang, W. Guan, J. Zhang, F. Wang and L. Zhao, The protective activities of water-soluble $C(60)$ derivatives against nitric oxide-induced cytotoxicity in rat pheochromocytoma cells, Biomaterials, 2010, 31, 8872-8881.

27 B. S. Yılmaz, M. L. Altun, I. E. Orhan, B. Ergene and G. S. Citoglu, Enzyme inhibitory and antioxidant activities of Viburnum tinus L. relevant to its neuroprotective potential, Food Chem., 2013, 141, 582-588.

28 X. Wu, Y. Lu, Y. Dong, G. Zhang, Y. Zhang, Z. Xu, D. J. Culley, G. Crosby, E. R. Marcantonio, R. E. Tanzi and Z. Xie, The inhalation anesthetic isoflurane increases levels of proinflammatory TNF- $\alpha$, IL-6, and IL-1 $\beta$, Neurobiol. Aging, 2012, 33, 1364-1378.

29 H. Wilms, J. Sievers, U. Rickert, M. Rostami-Yazdi, U. Mrowietz and R. Lucius, Dimethylfumarate inhibits microglial and astrocytic inflammation by suppressing the synthesis of nitric oxide, IL-1beta, TNF-alpha and IL-6 in an in vitro model of brain inflammation, $J$. Neuroinflammation, 2010, 7, 4002-4012.
$30 \mathrm{~J}$. Q. Qian, Cardiovascular pharmacological effects of bisbenzylisoquinoline alkaloid derivatives, Acta Pharmacol. Sin., 2002, 23, 1086-1092.

31 J. H. Xiao, Y. L. Zhang, X. L. Feng, J. L. Wang and J. Q. Qian, Effects of isoliensinine on angiotensin II-induced proliferation of porcine coronary arterial smooth muscle cells, J. Asian Nat. Prod. Res., 2006, 8, 209-216.

32 J. L. Wang, Y. Nong and M. X. Jing, Effects of liensinine on haemodynamics in rats and the physiologic properties of isolated rabbit atria, Yaoxue Xuebao, 1992, 27, 881-885.

33 P. A. Baeuerle and T. Henkel, Function and activation of NF$\kappa \mathrm{B}$ in the immune system, Annu. Rev. Immunol., 1994, 12, 141-179.

34 A. S. Baldwin Jr, The NF-kappa B and I kappa B proteins: new discoveries and insights, Annu. Rev. Immunol., 1996, 14, 649683.

35 T. Henkel, U. Zabel, Z. K. van, J. M. Müller, E. Fanning and P. A. Baeuerle, Intramolecular masking of the nuclear location signal and dimerization domain in the precursor for the p50 NF-кB subunit, Cell, 1992, 68, 1121-1133.

36 G. Shu, L. Zhang, S. Jiang, Z. Cheng, G. Wang, X. Huang and $\mathrm{X}$. Yang, Isoliensinine induces dephosphorylation of NF-kB p65 subunit at Ser536 via a PP2A-dependent mechanism in hepatocellular carcinoma cells: roles of impairing PP2A/ I2PP2A interaction, Oncotarget, 2016, 7, 40285-40296.

37 P. Poornima, V. B. Kumar, C. F. Weng and V. V. Padma, Doxorubicin induced apoptosis was potentiated by neferine in human lung adenocarcinoma, A549 cells, Food Chem. Toxicol., 2014, 68, 87-98.

38 R. Baskaran, P. Poornima, C. Y. Huang and V. V. Padma, Neferine prevents NF- $\kappa \mathrm{B}$ translocation and protects muscle cells from oxidative stress and apoptosis induced by hypoxia, Biofactors, 2016, 42, 407-417.

39 M. Y. Jun, R. Karki, K. R. Paudel, B. R. Sharma, D. Adhikari and D. W. Kim, Alkaloid rich fraction from Nelumbo nucifera targets VSMC proliferation and migration to suppress restenosis in balloon-injured rat carotid arter, Atherosclerosis, 2016, 248, 179-189.

40 G. Guan, H. Han, Y. Yang, Y. Jin, X. Wang and X. Liu, Neferine prevented hyperglycemia-induced endothelial cell apoptosis through suppressing ROS/Akt/NF- $\kappa \mathrm{B}$ signal, Endocrine, 2014, 47, 764-771.

41 M. L. Block, L. Zecca and J. S. Hong, Microglia-mediated neurotoxicity: uncovering the molecular mechanisms, Nat. Rev. Neurosci., 2007, 8, 57-69.

42 L. Qin, Y. Liu, T. Wang, S. J. Wei, M. L. Block, B. Wilson, B. Liu and J. S. Hong, NADPH oxidase mediates lipopolysaccharide induced neurotoxicity and proinflammatory gene expression in activated microglia, $J$. Biol. Chem., 2004, 279, 1415-1421.

43 A. I. Rojo, G. McBean, M. Cindric, J. Egea, M. G. Lopez, P. Rada, N. Zarkovic and A. Cuadrado, Redox control of microglial function: molecular mechanisms and functional significance, Antioxid. Redox Signaling, 2014, 21, 1766-1801. 
44 G. Gloire, S. Legrand-Poels and J. Piette, NF-kappaB activation by reactive oxygen species: fifteen years later, Biochem. Pharmacol., 2006, 72, 1493-1505.

45 H. Fan, P. F. Wu, L. Zhang, Z. L. Hu, W. Wang, X. L. Guan, H. Luo, M. Ni, J. W. Yang, M. X. Li, J. G. Chen and
F. Wang, Methionine sulfoxide reductase A negatively controls microglia-mediated neuroinflammation via inhibiting ROS/MAPKs/NF- $\mathrm{B}$ signaling pathways through a catalytic antioxidant function, Antioxid. Redox Signaling, 2015, 22, 832-847. 